Asteroid C. Estimated Magnitude 18

\begin{tabular}{lll} 
Plate & \multicolumn{2}{c}{ Exposure } \\
2739 & 1h & $50 \mathrm{~m}$ \\
2740 & 2 & 16 \\
2741 & 2 & 20 \\
2742 & 2 & 20
\end{tabular}

G.M.T. of mid-exposure 1913, Feb. $10^{\mathrm{d}} 22^{\mathrm{h}} 11 \mathrm{~m} 00^{\mathrm{s}}$

$\begin{array}{llll}11 & 19 & 29 & 00\end{array}$

$\begin{array}{llll}11 & 21 & 55 & 00\end{array}$

$\begin{array}{llll}12 & 20 & 48 & 00\end{array}$

\begin{tabular}{llllll} 
& \multicolumn{1}{c}{ App. $a$} & \multicolumn{3}{c}{ App. $\delta$} \\
9 h & $02 \mathrm{~m} 32 \mathrm{~s} 2$ & $+5^{\circ}$ & $\mathbf{3 8 ^ { \prime }}$ & $\mathbf{3 4}$ \\
9 & 01 & 45.2 & +5 & 44 & 10 \\
9 & 01 & 39.8 & +5 & 44 & 50 \\
9 & 00 & 49.7 & +5 & 51 & 00
\end{tabular}

Heber D. Curtis.

\title{
ELEMENTS OF THREE ASTEROIDS DISCOVERED IN THE SEARCH FOR 1911 MT (719), ALBERT
}

The following elements have been derived from the observations given above of the three asteroids discovered by Dr. H. D. Curtis in his search for the asteroid 1911 MT (719), Albert. The details of the

\section{AsteroId A}

Epoch, 1913 Gr.M.T. $=$ Feb. 9.7875

$M=299^{\circ} \quad 2^{\prime} 22^{\prime \prime}$

$\delta=192 \quad 44 \quad 49$

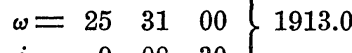

$i=\begin{array}{lll}9 & 00 & 30\end{array}$

$\log e=9.24300$

$\mu=581 " 0$

$\log a=0.52930$

Computers: C. C. Kiess,

J. H. Pitman. investigations which have led to the identification of these asteroids as new objects will be printed at a later date in connection with the investigations on the orbit of Asteroid (719), Albert.

\begin{tabular}{|c|c|c|}
\hline Aste & OID & \\
\hline eb. 11. & 50 & \\
\hline $\begin{array}{ll}30 & 14\end{array}$ & 57 & \\
\hline $16 \quad 23$ & 00 & \\
\hline $26 \quad 10$ & 49 & 1913.0 \\
\hline $\begin{array}{ll}6 & 33\end{array}$ & 46 & \\
\hline .49733 & & \\
\hline 47".8 & & \\
\hline 4923 & & \\
\hline
\end{tabular}

E. S. Haynes,

J. H. Pitman.
AsteroId C

Feb. 11.9071

$\begin{array}{lll}330 & 37 & 06\end{array}$

$\begin{array}{lll}200 & 10 & 34\end{array}$

$\begin{array}{lll}349 & 09 & 21 \\ 4 & 1913.0\end{array}$

$\left.\begin{array}{lll}6 & 21 & 01\end{array}\right\}$

9.42622

868 "74

0.40742

C. C. Kiess,

J. H. Pitman.

Berkeley Astronomical Department, April 2, 1913.

E. S. Haynes.

\footnotetext{
Issued December 17, 1913.
} 